\title{
REPRODUCTIVE POTENTIAL OF THE MALE RAT: ENHANCEMENT OF COPULATORY LEVELS FOLLOWING LESIONS OF THE MAMMILLARY BODY IN SEXUALLY NON-ACTIVE AND ACTIVE ANIMALS
}

\author{
R. D. LISK \\ Department of Biology, Princeton University, \\ Princeton, New Jersey 08540, U.S.A. \\ (Received 4th November 1968, revised 28th February 1969)
}

Experimenters interested in determining the pattern of copulatory activity in the male rat invariably select a sample of animals found to be active copulators during a series of pre-experimental trials. Various investigators have observed that a certain percentage of seemingly healthy males refuse to copulate under standard testing conditions (Whalen, Beach \& Kuehn, 1961). In my studies I define 'active copulators' as males which mate on a minimum of 4 out of 14 nights when in the constant presence of a stimulus female. In some samples, $40 \%$ fail to meet this criterion (Lisk, 1966).

Grunt \& Young (1952, 1953) found that changes in the level of androgens exceeding maintenance levels did not influence the sex drive in guinea-pigs. Larsson (1966) found this to be true for the rat also. Androgen therapy has not proved successful for initiation of sexual activity in the non-copulator (Whalen et al., 1961).

Recent experiments by Heimer \& Larsson (1964) and Lisk (1966) showed that the copulatory activity of the sexually active male rat could be increased following placement of lesions in the basal midline at the junction of the diencephalon and mesencephalon. The present experiments attempt to examine further the 'inhibition' concept by placing midline mammillary lesions in a group of sexually active and non-active rats.

Male rats of both Wistar and Sprague-Dawley strains were used as subjects. The method of lesion production was as previously described (Lisk, 1966).

A detailed analysis of the copulatory pattern was made for five active copulators of each strain. This included timing the following components of the copulatory pattern: mounting frequency (number of mounts without intromission), intromission frequency; ejaculation latency (time from introduction of female into cage until ejaculation); refractory period (time from ejaculation until next mount). The animals were maintained under reversed lighting conditions and testing was carried out in a circular plastic cylinder of 15 in. diameter, during the dark phase of the cycle. All tests were of 10 min duration. Since each animal served as its own control, statistical analysis was based upon the Wilcoxon matched-pairs sign-ranked test (two-tailed). 
The animals were observed for 9 days before lesioning, and for the first 14 days following lesioning. Then the stimulus female was replaced in the cage with the same male and 24-hr access to the female was permitted for 14 days. Counts of copulation plugs were made daily. The above protocol of mating tests and free access was repeated a second time.

A sham-lesioned group was run along with the sexually active and nonactive rats during periods when each male had free access to a sexually receptive female. The mean number of copulations per day based on a 28-day pre-lesion

TABLE 1

MEAN NUMBER OF GOPULATION PLUGS PER DAY FOR SEXUALLY ACTIVE ANIMALS, BASED ON A 28-DAY INTERVAL BEFORE AND AFTER LESIONING

\begin{tabular}{l|c|c|c}
\hline & No. of animals & Pre-lesion & Post-lesion \\
\cline { 2 - 3 } & 10 & $0 \cdot 629 \pm 0 \cdot 180$ & $0.722 \pm 0 \cdot 180$ \\
Controls & 10 & $0 \cdot 771 \pm 0 \cdot 160$ & $1 \cdot 229 \pm 0.071^{* *}$ \\
\hline
\end{tabular}

$* * P<0.01$.

TABLE 2

ANALysis OF COPUlatory PATTERN IN SEXUALly AGTIVE MALE RATS BEFORE AND AFTER PLACEMENT OF MAMMILLARY LESIONS

\begin{tabular}{|c|c|c|c|c|c|}
\hline Behavioural component & Strain & $\begin{array}{c}\text { Pre- } \\
\text { operative* } \\
\text { mean }\end{array}$ & $\begin{array}{c}\text { Post- } \\
\text { operative } 1 \dagger \\
\text { mean }\end{array}$ & $\begin{array}{c}\text { Post- } \\
\text { operative } 2 \ddagger \\
\text { mean }\end{array}$ & $P$ \\
\hline Ejaculations/test & $\begin{array}{l}\text { Sprague-Dawley } \\
\text { Wistar }\end{array}$ & $\begin{array}{l}0.91 \\
0.71\end{array}$ & $\begin{array}{l}1.20 \\
0.84\end{array}$ & $\begin{array}{l}1.23 \\
1.05\end{array}$ & $<0.01$ \\
\hline $\begin{array}{l}\text { Mounts before } \\
\text { ejaculation }\end{array}$ & $\begin{array}{l}\text { Sprague-Dawley } \\
\text { Wistar }\end{array}$ & $\begin{array}{l}6 \cdot 9 \\
3 \cdot 7\end{array}$ & $\begin{array}{l}4 \cdot 5 \\
3 \cdot 0\end{array}$ & $\begin{array}{l}8 \cdot 3 \\
4 \cdot 4\end{array}$ & N.S. \\
\hline $\begin{array}{l}\text { Intromissions before } \\
\text { ejaculation }\end{array}$ & $\begin{array}{l}\text { Sprague-Dawley } \\
\text { Wistar }\end{array}$ & $\begin{array}{l}14 \cdot 4 \\
12 \cdot 3\end{array}$ & $\begin{array}{l}12 \cdot 2 \\
10 \cdot 8\end{array}$ & $\begin{array}{l}11 \cdot 6 \\
10 \cdot 0\end{array}$ & N.S. \\
\hline $\begin{array}{l}\text { Ejaculation latency } \\
\text { (sec) }\end{array}$ & $\begin{array}{l}\text { Sprague-Dawley } \\
\text { Wistar }\end{array}$ & $\begin{array}{l}332 \cdot 8 \\
337 \cdot 0\end{array}$ & $\begin{array}{l}249 \cdot 1 \\
249 \cdot 6\end{array}$ & $\begin{array}{l}224 \cdot 8 \\
275 \cdot 6\end{array}$ & $<0.001$ \\
\hline $\begin{array}{l}\text { Refractory period } \\
(\mathrm{sec})\end{array}$ & $\begin{array}{l}\text { Sprague-Dawley } \\
\text { Wistar }\end{array}$ & $\begin{array}{l}280 \cdot 2 \\
271 \cdot 6\end{array}$ & $\begin{array}{l}281 \cdot 3 \\
257 \cdot 3\end{array}$ & $\begin{array}{l}258 \cdot 4 \\
296 \cdot 9\end{array}$ & N.S. \\
\hline
\end{tabular}

Five animals per group. Test period was $5 \mathrm{~min}$.

* Based on 9 consecutive days testing.

$\dagger$ Based on 14 consecutive days (1 to 14 ) following lesioning.

$\ddagger$ Based on 14 consecutive days (29 to 42 ) following lesioning.

period and one or two 28-day periods after lesioning has been used to determine any effects of lesioning. Analysis for any significant changes was made by covariance followed by Dunnett's $t$-test for multiple comparisons with a control.

Following production of medial mammillary lesions, sexually active animals of both strains showed increased levels of copulatory activity when measured as mean number of copulation plugs per 24-hr interval (Table 1). Detailed analysis of the copulatory activity based on 10 -min periods showed that more copulations occurred following lesioning, due mainly to a decrease in the ejaculatory latency (Table 2). No decrease was noted in the refractory period. 
Mammillary lesions in the sexually non-active animals also resulted in a sustained increase in the level of copulatory activity (Table 3), for at least 8 weeks following lesioning. By contrast, similar sized lesions placed in the dorsal thalamus of another group of sexually non-active animals resulted in a significant increase of copulatory activity only for the first 28 days following lesioning. Since the sham-lesioned groups, both sexually active and non-active, did not show an increase in copulations, it does not appear likely that the increases found in the lesioned groups can be attributed to an adaptation phenomenon. The apparent short-lasting increase in activity after the thalamic lesions may have resulted from irritative effects produced at lesioning.

The lesions producing these changes were small and confined to basal midline structures at the level of the mammillary bodies and interpeduncular nucleus. In no instance were these structures totally destroyed.

No changes in body or organ weights were detected in any of the lesioned animals.

\section{TABLE 3}

MEAN NUMBER OF COPULATION PLUGS PER DAY FOR SEXUALLY NON-ACTIVE MALES, BASED ON 28 DAYS PRE-LESIONING AND TWO 28-DAY INTERVALS POST-LESIONING

\begin{tabular}{l|c|c|c|c}
\hline & $\begin{array}{c}\text { No. of } \\
\text { animals }\end{array}$ & \multicolumn{1}{|c|}{ Pre-lesion } & Post-lesion 1 & Post-lesion 2 \\
\hline Sham & 7 & $0.096 \pm 0.017$ & $0.076 \pm 0.012$ & - \\
Mammillary & 9 & $0.087 \pm 0.008$ & $0.263 \pm 0.036 * *$ & $0.259 \pm 0.091^{*}$ \\
Dorsal thalamus & 8 & $0.084 \pm 0.006$ & $0.242 \pm 0.052^{*}$ & $0.210 \pm 0.062$ \\
\hline
\end{tabular}

The present experimental findings support the concept of 'inhibitory' areas participating in the integrative mechanism regulating sex drive in the male rat. Timed mating tests showed that the number of copulations per unit time increased due to a decrease in the time required between the initial mount and ejaculation. Heimer \& Larsson (1964) noted a similar response but, in addition, found a decrease in the refractory period between succeeding copulations. No change was noted in this measure during the present experiments. This difference could possibly result from the use of relatively massive lesions by Heimer and Larsson which destroyed not only the mammillary region but also the posterior parts of the medial thalamic nuclei and rostral part of the central grey matter in the mesencephalon.

Excellent technical assistance was provided by Alice Suydam and Clara Gudolonis. This research was made possible through Grant HD-02615 from the National Institute of Child Health and Human Development, U.S.P.H.S.

\section{REFERENCES}

Dunnetr, C. W. (1964) New tables for multiple comparisons with a control. Biometrics, 20, 482.

GRUNT, J. A. \& Young, W. C. (1952) Differential reactivity of individuals and the response of the male guinea pig to testosterone propionate. Endocrinology, 51, 237. 
Grunt, J. \& Young, W. G. (1953) Consistency of sexual behavior patterns in individual male guinea pigs following castration and androgen therapy. 7. comp. physiol. Psychol. 46, 138.

Heimer, L. \& Larsson, K. (1964) Drastic changes in the mating behavior of male rats following lesions in the junction of diencephalon and mesencephalon. Experientia, 20, 460.

LARsson, K. (1966) Individual differences in reactivity to androgen in male rats. Physiol. Behav, 1, 255.

Lisk, R. D. (1966) Increased sexual behavior in the male rat following lesions in the mammillary region. F. exp. Zool. 161, 129.

Whalen, R. E., BeAch, F. A. \& Kuehn, R. E. (1961) Effects of exogenous androgen on sexually responsive and unresponsive male rats. Endocrinology, 69, 373. 